\title{
Evaluation of Quality Properties of Melissa Leaves by Different Drying Methods
}

\section{Ginat El-sherif and Hasnaa M. Abo Taleb}

Department of Horticultural Crops Tech. Res., Food Technology Research Institute, Agricultural Research Center, Giza, Egypt..

Received: 25 August 2020 / Accepted 10 Oct. 2020 / Publication date: 20 Oct. 2020

\begin{abstract}
The objective of this study was to evaluation the quality properties of Melissa leaves by different drying methods on contents of total phenolic, total flavonoids, chlorophyll a, chlorophyll $b$, total carotenoids, total color density, browning index and essential oils, results showed that all methods of drying used (ventilated oven, microwave \& shade and shade-drying) significantly decreased in content of these properties when compared with fresh leaves. The less effect was observed using microwave \& Shade followed by Shade-drying while the greatest effect was observed using ventilated oven. Different drying methods which used had effect on the content of Melissa leaves essential oil. The main components of the essential oil of microwave \& Shade were 4-hydroxy-7-methylcoumarin and $\beta$ Carotene, while in shade-drying were 3, 2, 4, 5-Tetramethoxyflavone, iso Vitexin and4hydroxy-7-methylcoumarin but in ventilated oven were 4-hydroxy-7-methylcoumarin and Petunidin cation.
\end{abstract}

Keywords: Melissa, drying, chlorophylls, carotenoids, total color density, browning index, essential oil.

\section{Introduction}

Lemon balm (Melissa officinalis L.) is a therapeutic herb of the Lamiaceae family. Lemon balm is a lasting upstanding, shaggy and bushy fragrant herb, develops from 70 to $150 \mathrm{~cm}$ tall, and with oil rich leaves (Elahe Pouyanfar et al. 2018). For over 2000 years, fragrant leaves of this plant have been generally utilized in cooking to add flavor to dishes. According to Mileveskaye et al. (2017), Melissa officinalis $L$. has a high focus from phenolic acids, especially caffeic corrosive subsidiaries, for example, rosmarinic acid.

The fundamental oil substance in Melissa officinalis L. was ranged from $0.02-0.30 \%$ (Prawal, et al. 2015), which utilized in fragrant healing. Fundamental oil substance relies upon different natural and hereditary elements, just as postharvest handling factors and the proportion between various oil constituents assume a job in their bioactivity (Lemos et al. 2017).

Phytochemical examination of the plant leaves has uncovered the nearness of flavonoids (cynaroside,cosmosin, rhamnocitrin, isoquercitrin and luteolin), terpenes and triterpene acids (ursolic and oleanolic acids)(Patora et al. (2003) and Shakeel et al., 2017).

Melissa officinalis L. is listed in a number of European pharmacopoeias for its carminative digestive, diaphoretic and stimulant activities, calmative, antiseptic, antimicrobial, antioxidative and possesses antiviral activity. In addition, it inhibits thyroid activity (Shakeel et al. 2017).

Ghasemi et al. (2013), reported that, the maximum essential oil content (0.43\%) obtained in 48 hrs. oven-drying while minimum content $(0.03 \%)$ obtained from drying under microwave with the power of $500 \mathrm{~W}$. Citral and Citronellal content percentage in shade-drying with an air flow fan were more than other drying methods, finally they suggested that oven-drying method has better results compared to the other methods. Generally, lemon balm dry herb is dried in the shade to preserve the chemical composition of the plant. Too much direct sunlight will cause volatile oils to disappear. The volatile oil is obtained by steam distillation of the dried herb.

Drying food, agricultural, medicinal plants and biological active materials is a significant activity in agriculture, food (Koyuncu et al., 2007). Generally, restorative and aromatic plants must be dried following harvest since they are exposed to antioxidant compound and microbiological corruptions. Drying is the postharvest activity of expelling the exorbitant dampness from recently gathered plants. Drying techniques and conditions influence drying time and quality parameters of

Corresponding Author: Ginat El-sherif, Department of Horticultural Crops Tech. Res., Food Technology Research Institute, Agricultural Research Center, Giza, Egypt. 
restorative and sweet-smelling plants (Cuervo and Hensel, 2008). The most well-known strategy for drying restorative and sweet-smelling plants is convective air-drying. In convective air-drying, encompassing air or warmed air is constrained through drying plants and the air picks up dampness from drying materials. Diverse drying strategies were utilized to locate the proper drying strategy and conditions for aeronautical pieces of coriander. They were sun drying (uncovering straightforwardly with daylight), conceal drying (under shadow) broiler drying $\left(40\right.$ and $\left.60{ }^{\circ} \mathrm{C}\right)$, microwave drying $(500$ and $700 \mathrm{~W}$ ) and freeze-drying (Pirbalouti, et al., 2017).

According to Dimitrios, et al. (2009), color is considered to play a significant role in determining the quality of food materials since it has a great influence on their appearance, processing and acceptability. Dried lemon balm leaves exhibit insufficient color quality as compared to the fresh ones. During hot-air drying the discoloration in leaves from bright green to pale green occurs mainly due to loss of chlorophyll which is sometimes accompanied by browning.

The purpose of the present study was to evaluate the quality a property of Melissa leaves which drying by different drying methods such as: ventilated oven, microwave \& shade and shade-drying.

\section{Materials and methods}

\section{Materials:}

Lemon balm (Melissa officinalis L) was collected from an organic farm at Elmaryotia, Giza, in season March 2019 before flowering. Prior to drying experiments, the leaves were manually separated from the stalks.

Chemicals used in this study were of analytical grade and purchased from El-Gomhoria Co.

\section{Drying methods:}

Melissa (Melissa officinalis L) leaves were carefully separated from the stems and washed. Then, it dried on the same day by the three drying methods: convection oven drying, microwave drying + shade drying and under shadow. For each drying method, $500 \mathrm{~g}$ of fresh leaves was used. The conditions of dehydration were as follows:

1. Convection oven drying at $40^{\circ} \mathrm{C} \pm 1^{\circ} \mathrm{C}$ for 2.30 hours.

2. Microwave oven drying at $100 \mathrm{~W}$ for 10 min.after this treatment put it in shadow for $5 \mathrm{~min}$.

3. Air drying (shade drying) for about 13 hours at room temperature (mean temperature $25^{\circ} \mathrm{C}$ ).

\section{Chemical analyses:}

Total phenolic compounds were determined using folin-denis reagent as described by (Singleton et al., 1999). The concentrations of flavonoids in methanol extract were measured spectrophotometrically at 440nm according to Zhisen, (1999). Volatile oil was determined by (ISO, 2009). Chlorophyll (a \& b) and total carotenoids were determined by the method of Yang et al. (1998). The absorbance spectrum of each supernatant was measured and the absorption maxima were read at $663 \mathrm{~nm}$ for Chlorophyll $a, 646 \mathrm{~nm}$ for Chlorophyll $b$ and $440 \mathrm{~nm}$ for carotenoids (UV/VIS spectrophotometer Cary 50 Scan). Contents of Chlorophyll $a, b$ and carotenoids were calculated from the following equations (1):

Chlorophyll a $(\mu \mathrm{g} / \mathrm{ml})=12.25 \mathrm{A663}-2.25 \mathrm{A646}$

Chlorophyll $b(\mu \mathrm{g} / \mathrm{ml})=20.31$ A646-4.91A663

Carotenoids $(\mu \mathrm{g} / \mathrm{ml})=4.69$ A440-0.267 $($ Chl $a+$ Chl $b)$,

\section{GC-MS analysis:}

The Analyses were performed using a GC-MS system (Hewlett-Packard 6890 gas chromatograph coupled to a 5973A mass spectrometer), equipped with split/split less injector in the split less mode and at $250^{\circ} \mathrm{C}$ during the chromatographic run. The volatile compounds were separated in a capillary column $(30 \mathrm{~m} \times 0.25 \mathrm{~mm}, 0.25 \mu \mathrm{m}$ film thickness, HP-5MS) using N2 $(99.99 \%)$ as a carrier gas at a $1 \mathrm{~mL} / \mathrm{min}$ flow rate. The oven temperature was varied as follows: $60^{\circ} \mathrm{C}(5 \mathrm{~min})$, then warmed to $250^{\circ} \mathrm{C}$ at $5^{\circ} \mathrm{C} / \mathrm{min}$, then held $10 \mathrm{~min}$ at $250^{\circ} \mathrm{C}$. The mass detector conditions were: transfer line temperature of $220^{\circ} \mathrm{C}$, ion source temperature of $220^{\circ} \mathrm{C}$ and ionization mode with electron impact at $70 \mathrm{eV}$. The Covets retention index (RI) values were calculated using a homologous series of $\mathrm{n}$ alkanes $(\mathrm{C} 8-\mathrm{C} 25)$ and values were compared with values reported in the literature and available 
Adams data12. All mass spectra were also compared with the data system library (Wiley 275). Identification of volatile compounds was achieved by matching mass spectra and retention indices (RI) with those obtained from Wiley library as well as from literature data (Khalili et al., 2017).

5. Total color density: (TCD) of all products $(1 \mathrm{gm})$ was extracted by $25 \mathrm{ml}$ water, then filtered and the color value was measured at 420,520 and $700 \mathrm{~nm}$. TCD was calculated from the following equations (2): (Somers, 1971, 1972).

$$
T C D=A b s 420+A b s 520)-2(A b s 700) .
$$

6. Browning index: Browning index was determined according to the method of Meydev et al. (1977), as its light absorbance at $420 \mathrm{~nm}$.

\section{Statistical analysis}

Data obtained were statistically analyzed by SPSS computer software SPSS 2000. The results were expressed as mean \pm standard deviation (SD) and tested for significance using one way analysis of variance ANOVA test, according to Armitage and Berry, (1987).

\section{Results and Discussion}

\section{Total phenolic and flavonoid content:}

The bioactivity of Melissa extracts is mainly attributed, as for any other plant formulation, to the comprised phenolic acids, flavonoids and terpenoids. Subjective and quantitative arrangement of Melissa extricates relies upon the inborn fluctuation of the material (e.g., beginning, collect time, phenological period of improvement) and the medicines (e.g., drying, extraction boundaries) applied (Skrovankova et al., 2012). It is well known that plant flavonoids and phenolics in general are highly effective free radical scavenging and they are antioxidants. Polyphenol and flavonoids are utilized for the counteraction and fix of different sicknesses which are basically connected with free radical (Deepa et al., 2009).

The content of total phenols and flavonoids compounds in Melissa leaves are presented in Table (1) and the results appeared that there were significant differences $(P \geq 0.05)$ between the values obtained for fresh and drying leaves, also there were significant differences $(\mathrm{P} \geq 0.05)$ in drying leaves which is related to the different drying method, whereas fresh leaves content the highest value for total phenols and flavonoids compounds when compared with drying leaves which were 4.60 and 2.80 $\mathrm{mg} / \mathrm{g}$ respectively. On the other hand, it was observed that Microwave \& Shade content the highest value of total phenols and flavonoids compounds followed by Shade-drying, while Ventilated oven had the lowest value. Atanassova et al. (2011) found that the content of total phenolic and total flavonoids in lemon balm (Melissa officinalis) varying between $48.86 \mathrm{mg} \mathrm{GAE} / 100 \mathrm{~g}$ to $45.06 \mathrm{mg} \mathrm{CE} /$ $100 \mathrm{~g}$.

Table 1: Effect of different drying methods on the content of total phenolic and total flavonoid compounds of Melissa leaves ( $\mathrm{mg} / \mathrm{g}$ )

\begin{tabular}{|c|c|c|c|c|}
\hline \multirow[b]{2}{*}{ Components } & \multirow[b]{2}{*}{ Fresh leaves } & \multicolumn{3}{|c|}{ Drying Methods } \\
\hline & & Ventilated oven & $\begin{array}{c}\text { Microwave } \boldsymbol{\&} \\
\text { Shade }\end{array}$ & $\begin{array}{c}\text { Shade - } \\
\text { drying }\end{array}$ \\
\hline Total phenolic compounds & $\begin{array}{c}4.600^{\mathrm{a}} \pm \\
0.0721\end{array}$ & $\begin{array}{c}0.4867^{\mathrm{d}} \pm \\
0.0057\end{array}$ & $\begin{array}{c}3.510^{\mathrm{b}} \pm \\
0.0818\end{array}$ & $\begin{array}{c}3.383^{\mathrm{c}} \pm \\
0.0513\end{array}$ \\
\hline Total flavonoids compounds & $\begin{array}{c}2.800^{\mathrm{a}} \pm \\
0.0800\end{array}$ & $\begin{array}{c}0.616^{\mathrm{d}} \pm \\
0.0404\end{array}$ & $\begin{array}{c}1.880^{\mathrm{b}} \pm \\
0.1389\end{array}$ & $\begin{array}{c}0.810^{\mathrm{c}} \pm \\
0.0300\end{array}$ \\
\hline
\end{tabular}

\section{Chlorophyll (a \& b) and total carotenoids content:}

Pigments are viewed as mixes with wholesome enthusiasm since their essence in plant items is connected, aside from shading, likewise with the cancer prevention agent potential and provitamin A dynamic (Bernal et al., 2011). The results in Table (2) showed that, the Chl. a content in fresh leaves was $5.588 \mathrm{mg} / \mathrm{g}$ while it varied from 2.937 to $0.059 \mathrm{mg} / \mathrm{g}$ in drying leaves. The content of Chl. b was 
$4.289 \mathrm{mg} / \mathrm{g}$ in fresh leaves, which ranged from 0.059 to $2.937 \mathrm{mg} / \mathrm{g}$ in drying leaves. On the other hand, content of carotenoids in fresh leaves and drying by ventilated oven, microwave \& shade and shade drying were $1.465,0.035,0.868,0.088 \mathrm{mg} / \mathrm{g}$ respectively.

According to the results in Table (2) there are significant differences $(\mathrm{P} \geq 0.05)$ between fresh and drying leaves by different drying method in content of chlorophylls $\mathrm{a}, \mathrm{b}$ and total carotenoids, while it observed that there are no significant differences between ventilated oven and microwave \& shade in content of total carotenoids. On the other hand, the microwave \& shade followed by shade drying were the better dehydrating process to preserve the content of chlorophylls $\mathrm{a}, \mathrm{b}$ and total carotenoids compered to ventilated oven. Lenka et al. (2015) observed that higher content of pigments in Melissa officinalis when microwave drying procedure was applied compared to the oven dried samples and the sun-dried samples (air dried with sun exposure) but a significant difference was only observed in the content of chlorophyll b. All methods of drying used (air drying, oven drying, microwave drying) significantly decreased the yield of carotenoids in the edible parts of leafy vegetables; the greatest reduction was observed using microwave drying method and less effect was observed using air drying (Kamel et al., 2013).

Table 2: Effect of different drying methods on chlorophyll (a \& b) and total carotenoids content of Melissa leaves (mg/g)

\begin{tabular}{lcccc}
\hline \multirow{2}{*}{ Components } & Fresh leaves & Ventilated & Drying Methods \\
\cline { 3 - 5 } & & $\begin{array}{c}\text { Microwave \& } \\
\text { oven }\end{array}$ & $\begin{array}{c}\text { Shade- } \\
\text { drying }\end{array}$ & $3.636^{\mathrm{b}} \pm$ \\
\multirow{2}{*}{ Chlorophyll a } & $5.589^{\mathrm{a}} \pm$ & $0.856^{\mathrm{d}} \pm$ & 0.0550 & 0.0300 \\
\hline \multirow{2}{*}{ Chlorophyll b } & 0.0215 & 0.0350 & $2.940^{\mathrm{b}} \pm$ & $1.687^{\mathrm{c}} \pm$ \\
& $4.287^{\mathrm{a}} \pm$ & $0.059^{\mathrm{d}} \pm$ & 0.0100 & 0.0351 \\
\hline \multirow{2}{*}{ Total carotenoids } & 0.0351 & 0.0021 & $0.870^{\mathrm{b}} \pm$ & $0.089^{\mathrm{c}} \pm$ \\
& $1.467^{\mathrm{a}} \pm$ & $0.035^{\mathrm{c}} \pm$ & 0.0400 & 0.0085 \\
\hline
\end{tabular}

Mean values in the same row which is not followed by the same letter are significantly different $(\mathrm{p}<0.05)$

\section{Total color density and browning index content:}

Color is considered a significant role in determining the quality of food materials since it has a great influence on their appearance, processing and acceptability. Dried lemon balm leaves exhibit insufficient color quality as compared to the fresh ones. The method and temperature used for drying may have a considerable impact on the quality of the resulting medicinal plant materials. Chemical changes are the most important in the post-harvest of medicinal plants and can be influenced by drying. Moreover, drying can promote changes in the product appearance (color) and smell, modifying the final quality.

Results in Table (3) appeared that total color density was 0.182 in fresh leaves while it ranged from 0.063 to 0.138 in dried leaves, also it was observed that the highest value of browning index was in fresh leaves $(0.528)$, meanwhile, dried leaves by Microwave \& Shade recorded the highest value followed by Shade -drying and Ventilated oven which were $0.513,0.368$ and 0.187 respectively. there are significant differences $(\mathrm{P} \geq 0.05)$ between fresh and drying leaves by different drying method in content of total color density and browning index but there are no significant differences between Microwave \& Shade and Shade-drying

Table 3: Effect of different drying methods on total color density and browning index of Melissa leaves

\begin{tabular}{|c|c|c|c|c|}
\hline \multirow[b]{2}{*}{ Components } & \multirow[b]{2}{*}{ Fresh leaves } & \multicolumn{3}{|c|}{ Drying Methods } \\
\hline & & $\begin{array}{c}\text { Ventilated } \\
\text { oven }\end{array}$ & $\begin{array}{c}\text { Microwave \& } \\
\text { Shade }\end{array}$ & $\begin{array}{l}\text { Shade- } \\
\text { drying }\end{array}$ \\
\hline Browning index & $\begin{array}{c}0.530^{\mathrm{a}} \pm \\
0.0001\end{array}$ & $\begin{array}{c}0.187^{\mathrm{d}} \pm \\
0.0057\end{array}$ & $\begin{array}{c}0.513^{\mathrm{b}} \pm \\
0.0056\end{array}$ & $\begin{array}{c}0.370^{\mathrm{c}} \pm \\
0.0001\end{array}$ \\
\hline
\end{tabular}

Mean values in the same row which is not followed by the same letter are significantly different $(\mathrm{p}<0.05)$ 


\section{Composition of the essential oils:}

The essential oil of M. officinalis has potential calming exercises, supporting the conventional use of this plant in treating different infections related with irritation and agony (Bounihi et al., 2013). Argyropoulos and Müller (2014) reported that the method of drying had a significant effect on the quality and quantity of the essential oils and the proportion of the various components in medicinal plants, whereas, the loss of essential oil and the discoloration of fresh lemon balm samples occurred during drying but the amounts of these changes depended on the selected temperature profile of drying air (Murat and Sefa, 2019).

The composition of the essential oil content of fresh and dried M. officinalis leaves was shown in Table $(4,5,6,7)$. Results in Table (4) showed that fresh leaves content thirty components of essential oil and the major component was Scutellarin (51.43\%) followed by $\beta$-Citronellol, Astragalin $(14.11$ and $5.14 \%)$. On the other hand, results appeared that the components of essential oil Gardenin, Propyl gallate, 5,7,2-Trimethoxyflavone,3-(3,4-Dimethoxyphenyl)-4-methylcoumarin, 3,6,3,4Tetramethoxyflavone and 3,2,4,5-Tetramethoxyflavone were found in both fresh and dried Melissa leaves.

Table 4: Composition of the essential oils (\%) for Melissa leaves

\begin{tabular}{|c|c|c|c|}
\hline No. & Components & RT & Fresh leaves $(\%)$ \\
\hline 1 & 4-Hydroxychalcone & 3.912 & 0.73 \\
\hline 2 & 2,5-Dimethoxyflavone & 4.711 & 0.53 \\
\hline 3 & Dimethyl fraxetin & 4.989 & 0.66 \\
\hline 4 & 3,2,4,5-Tetramethoxyflavone & 5.425 & 0.88 \\
\hline 5 & 6,4-Dimethoxy-7-hydroxyisoflavon & 13.47 & 1.19 \\
\hline 6 & Scutellarin & 13.761 & 51.43 \\
\hline 7 & $\beta$-Citronellol & 14.77 & 14.11 \\
\hline 8 & Astragalin & 14.914 & 5.14 \\
\hline 9 & Geranyl isovalerate & 15.118 & 0.95 \\
\hline 10 & Apigenin 8-C-glucoside & 15.36 & 0.66 \\
\hline 11 & Hexa-hydro-farnesol & 15.656 & 1.85 \\
\hline 12 & Heptacene & 15.84 & 1.26 \\
\hline 13 & Nonacetate & 16.48 & 1.59 \\
\hline 14 & Ascorbic acid, per methyl & 16.578 & 0.95 \\
\hline 15 & Octacaine & 16.706 & 1.81 \\
\hline 16 & Phytane & 17.604 & 2.18 \\
\hline 17 & Crocetin & 17.731 & 1.76 \\
\hline 18 & (S)-(-)-Citronellic acid & 18.141 & 0.56 \\
\hline 19 & Eicosane & 18.682 & 0.74 \\
\hline 20 & Tertradecane,2,6,10- trimethyl & 19.064 & 1.35 \\
\hline 21 & Chromone,5-hydroxy-6,7,8-trimethoxy-2,3-dimethyl & 19.248 & 0.83 \\
\hline 22 & Long borneol & 20.257 & 0.7 \\
\hline 23 & Pentosane & 20.499 & 1.92 \\
\hline 24 & 5,7,2-Trimethoxyflavone & 20.839 & 0.63 \\
\hline 25 & 3-(3,4-Dimethoxyphenyl)-4-methylcoumarin & 21.237 & 0.68 \\
\hline 26 & $3,6,3,4$ Tetramethoxyflavone & 21.319 & 0.7 \\
\hline 27 & Gardenin & 21.463 & 0.63 \\
\hline 28 & Pentatriacontane & 21.606 & 1.64 \\
\hline 29 & Squalene & 22.783 & 0.73 \\
\hline 30 & Propyl gallate & 22.898 & 0.68 \\
\hline
\end{tabular}

RT: Retention time in minutes from GC.

Ghasemi Pirbalouti et al. (2013) found that drying of lemon balm caused not only the quality deterioration of the essential oil, but also resulted in some quantitative variations of relative proportion of the components. The chemical compounds fluctuation in different drying treatments (such as shade or oven drying) was reported previously in lemon balm (Sellami et al. 2011; Argyropoulos and Müller 2014). Results in Table (5) showed that 4-hydroxy-7-methylcoumarin, Petunidin cation, isoVitexi the major compounds of essential oil in ventilated oven drying leaves which were 25.52, 8.37 and $7.83 \%$ respectively. Also, it observed that, 4-hydroxy-7-methylcoumarin 
is represents the highest percentage in ventilated oven drying and Microwave \& Shade which were 25.52 and $11.35 \%$ respectively.

Table 5: Effect of ventilated oven drying on chemical composition of essential oils (\%) for Melissa leaves

\begin{tabular}{|c|c|c|c|}
\hline No. & Components & RT & Ventilated oven $(\%)$ \\
\hline 1 & 3,4,5-Trimethoxycinnamic acid & 5.084 & 1.93 \\
\hline 2 & 4,4-Sulfonylbisphenol & 8.471 & 3.63 \\
\hline 3 & 4-hydroxy-7-methylcoumarin & 10.263 & 25.52 \\
\hline 4 & Vitexin & 13.203 & 4.8 \\
\hline 5 & isoVitexin & 14.29 & 7.83 \\
\hline 6 & 3-(3,4-Dimethoxyphenyl)-4-methylcoumarin & 15.249 & 3.28 \\
\hline 7 & $\beta$ Carotene & 15.569 & 3.69 \\
\hline 8 & Petunidin cation & 16.652 & 8.37 \\
\hline 9 & 2,4-Dimethoxy-3-hydroxy-6-methylfavone & 17.341 & 4.62 \\
\hline 10 & Gardenin & 17.563 & 4.82 \\
\hline 11 & 5,7,2-Trimethoxyflavone & 18.034 & 2.64 \\
\hline 12 & 3-Hydroxy-6,2,3-trimethoxyflavone & 19.055 & 1.76 \\
\hline 13 & 3-Benzyloxy-5,6,7,4-tetramethoxyflavone & 19.236 & 4.65 \\
\hline 14 & Phytanic acid & 20.523 & 3.95 \\
\hline 15 & Propyl gallate & 21.347 & 0.95 \\
\hline 16 & $3,6,3,4$-Tetramethoxyflavone & 21.635 & 1.28 \\
\hline 17 & $3,2,4,5$-Tetramethoxyflavone & 22.225 & 4.04 \\
\hline 18 & 3-(3,4-Dimethoxyphenyl)-4-methylcoumarin & 22.336 & 3.92 \\
\hline 19 & 3- Benzyloxy 5,6,7,4-tetramethoxyflavone & 22.647 & 0.94 \\
\hline 20 & 3,2,4,5-Tetramethoxyflavone & 22.815 & 7.38 \\
\hline
\end{tabular}

RT: Retention time in minutes from GC.

Results in Table (6) appeared that the drying leaves by Microwave \& Shade contain twenty second components of essential oil which ranged from 11.35 to $0.17 \%$, meanwhile Shade-drying leaves contain twenty components of essential oil (Table 7) and the major components were 3,2,4,5Tetramethoxyflavone (13.24\%), isoVitexin (12.93\%) and 4-hydroxy-7-methylcoumarin (12.5\%). On the other hand, it was found that from the results compounds 3,4,5-Trimethoxycinnamic acid, 4,4Sulfonylbisphenol, Vitexin, isoVitexin, $\beta$ Carotene, Petunidin cation, 4-hydroxy-7-methylcoumarin, 2,4-Dimethoxy-3-hydroxy-6-methylfavone, 3-Benzyloxy-5,6,7,4-tetramethoxyflavone, Phytanic acid and 3- Benzyloxy 5,6,7,4-tetramethoxyflavone were shared in dried Melissa leaves by Ventilated oven, Microwave \& Shade and Shade-drying. Mirahmadi et al. (2017) found that Different drying treatments had a significant effect on the content of M. officinalis essential oil (ranging from 0.08 to $0.3 \% \mathrm{v} / \mathrm{w}$; overall average of $0.22 \% \mathrm{v} / \mathrm{w}$ ). The main components of the essential oil of shade dried, oven-dried at $35{ }^{\circ} \mathrm{C}$ and oven-dried at $55{ }^{\circ} \mathrm{C}$ samples were $\beta$-caryophyllene, geranial and $\gamma$-cadinene, respectively. Sellami et al. (2011) reported that the lowest amount of essential oil yield was resulted through oven drying at $55{ }^{\circ} \mathrm{C}$ which indicates that increasing the drying temperature would significantly decrease the essential oil content. At high temperatures, the biological structure of the oil glands of aromatic plants can be affected significantly, and the epithelial cells in the dried samples of some sensible plants can collapse resulting in more volatile oil diffusion during the drying, which could explain the loss of essential oil in high temperatures. 
Table 6: Effect of microwave \& shade-drying on chemical composition of essential oils (\%) for Melissa leaves.

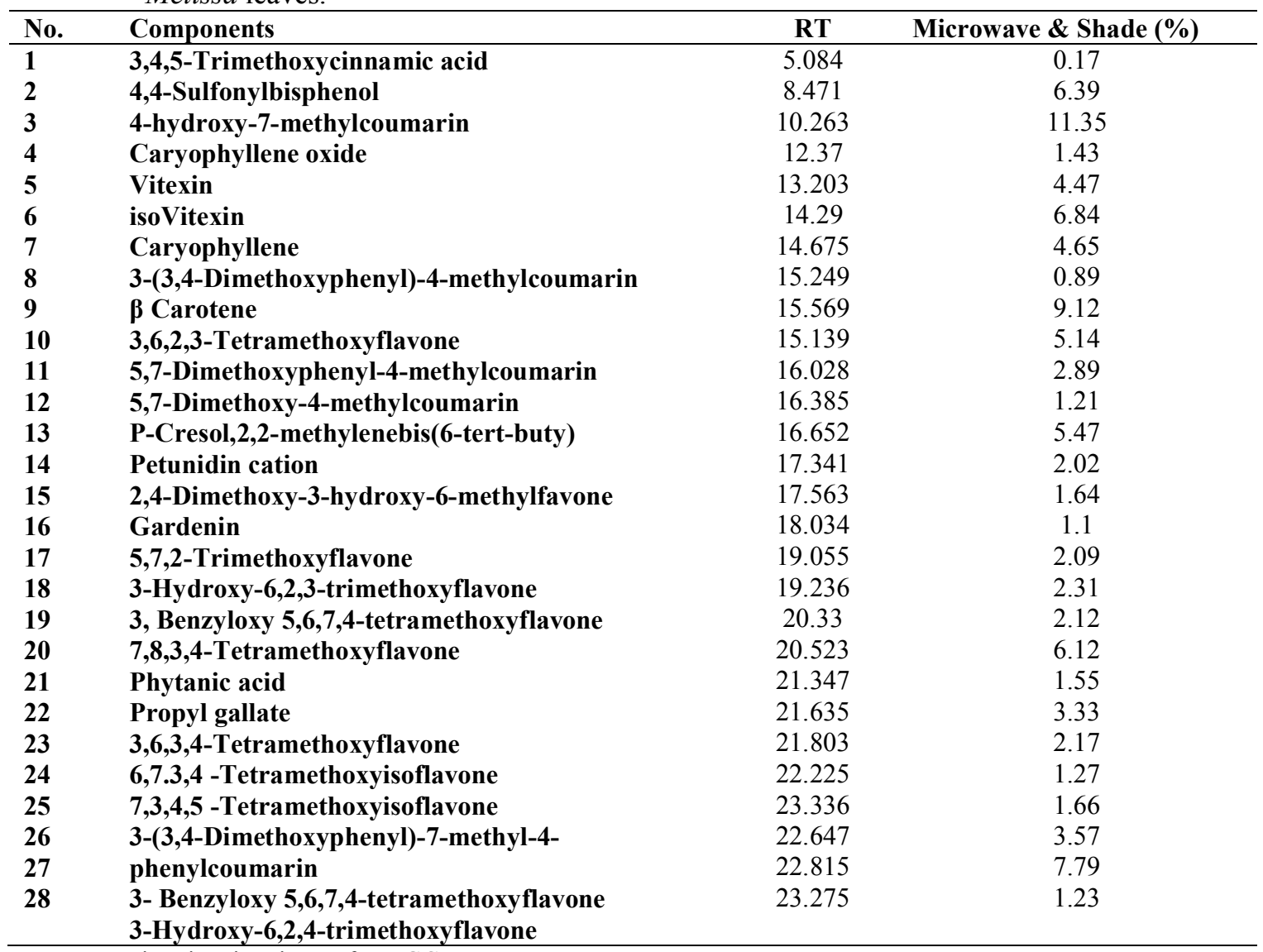

RT: Retention time in minutes from GC.

Table 7: Effect of different drying methods on chemical composition of essential oils (\%) for Melissa leaves

\begin{tabular}{|c|c|c|c|}
\hline NO. & Components & RT & $\begin{array}{c}\text { Shade } \\
\text { Drying }(\%)\end{array}$ \\
\hline 2 & 4,4-Sulfonylbisphenol & 8.471 & 6.91 \\
\hline 3 & 6,7.3,4 -Tetramethoxyisoflavone & 9.816 & 4.84 \\
\hline 4 & 4-hydroxy-7-methylcoumarin & 10.263 & 12.5 \\
\hline 6 & isoVitexin & 14.29 & 12.93 \\
\hline 7 & 3-(3,4-Dimethoxyphenyl)-4-methylcoumarin & 15.249 & 1.37 \\
\hline 8 & $\beta$ Carotene & 15.569 & 10.96 \\
\hline 9 & 3,6,2,3-Tetramethoxyflavone & 15.139 & 2.68 \\
\hline 10 & 5,7-Dimethoxy-4-methylcoumarin & 16.028 & 1.35 \\
\hline 14 & 5,7,2-Trimethoxyflavone & 18.034 & 1.28 \\
\hline 15 & 3-Hydroxy-6,2,3-trimethoxyflavone & 19.055 & 1.77 \\
\hline 16 & 3, Benzyloxy 5,6,7,4-tetramethoxyflavone & 19.236 & 2.65 \\
\hline 17 & Phytanic acid & 20.523 & 3.38 \\
\hline 18 & Propyl gallate & 21.347 & 1.71 \\
\hline 19 & 3,6,3,4Tetramethoxyflavone & 21.635 & 2.43 \\
\hline 20 & $3,2,4,5$-Tetramethoxyflavone & 22.815 & 13.24 \\
\hline
\end{tabular}

RT: Retention time in minutes from GC. 


\section{Conclusion}

Drying process has effect in quality attributes drying products, in addition, different drying methods have different effects on the quantity and quality of the essential oils produced from medicinal plants. The results presented in this study appeared that the proportions of the components of total phenolic, total flavonoids, chlorophyll a, chlorophyll b, total carotenoids, total color density, browning index and essential oils differed according to the drying method used. the results showed that the drying method by microwave $\&$ shade had the lowest effect on contents of these components, followed by shade-drying method, while the ventilated oven method had the largest effect on these ingredients.

\section{References}

Argyropoulos, D. and J. Müller, 2014. Changes of essential oil content and composition during convective drying of lemon balm (Melissa officinalis L.). Industrial Crops and Products, 52: 118-124.

Armitage, P. and G. Berry, 1987. Statistical Method in Medical Research". Blackwell, Oxford, UK: 93-213.

Atanassova M., S. Georgieva and K. Ivancheva, 2011. Total Phenolic and total flavonoid contents, antioxidant capacity and biological contaminants in medicinal herbs. Journal of the University of Chemical Technology and Metallurgy, 46 (1): 81-88.

Bounihi, A., G. Hajjaj, R. Alnamer, Y. Cherrah, and A. Zellou, 2013. In vivo potential antiinflammatory activity of Melissa officinalis L essential oil. Adv Pharmacol Sci., http://dx.doi.org/10.1155/2013/101759

Bernal, J., J.A. Mendiola, E. Ibáñez, and A. Cifuentes, 2011. Advanced analysis of nutraceuticals. J. Pharm. Biomed. Anal., 55: 758-774.

Cuervo, S.P., and O. Hensel, 2008. Drying of Lemon Balm (Melissa Officinalis L.) using stepwise process control, Tropentag 2008, University of Hohenheim, 7-9 Ekim, Germany.

Deepa, V.S., P.S. Kumar, S. Latha, P. Selvamani, and S. Srinivasan, 2009. Medicinal plants and traditional medicine in Africa. Africa J Biotech, 8(8); 1630-1636.

Dimitrios A., K. Joseph and M. Joachim, 2009. Color degradation of lemon balm (Melissa officinalis L.) as affected by the drying process. Food Processing, Monitoring Tech. In Bioprocesses and Food Quality Management Potsdam, Germany.

Elahe, P., H. Javad, A. Mohammad, H. Mehrnaz, R.K. Mohammad and G. Mansour, 2018. Analysis of phytochemical and morphological variability in different wild-and agro-ecotypic populations of Melissa officinalis L. growing in northern habitats of Iran. Industrial Crops and Products, 112: 262-273.

Ghasemi, M., M. Jafarpour, and M. Forogh, 2013. Effect of different drying methods on the quality and quantity of the essential oil of lemon balm (Melissa officinalis L.). International Journal of Agriculture and Crop Sciences, 6 (9): 501-504.

Ghasemi, P.A., M. Oraie, M. Pouriamehr and E.S. Babadi, 2013. Effects of drying methods on qualitative and quantitative of the essential oil of Bakhtiari savory (Satureja bachtiarica Bunge.). Industrial Crops and Products, 46: 324-327.

ISO, 2009. International Standard Organization (ISO 6571). Spices, Condiments and HerbsDetermination of Volatile Oil Content (Hydro distillation Method).

KamelL, M.S., A.H. Thabet, and A.E. Algadi, 2013. Influence of Drying Process on the Functional Properties of Some Plants. Chemistry and Materials Research, 3(7), 1-8.

Khalili, G., A. Mazloomifar, K. Larijani, T.M. Saber, and A.P. Abroomand, 2017.Supercritical fluid extraction as a technique to obtain essential oil from Rosmarinus officinalis L. Orient. J. Chem., 33 (5): 2537-2541.

Koyuncu, T., I. Tosun, and Y. Pinar, 2007. Drying characteristics and heat energy requirement of cornelian cherry fruits (cornus mas L.). Journal of Food Engineering, 78 (2):735-739.

Lemos, M.F., M.F. Lemos, H.P. Pacheco, A.C. Guimarães, M. Fronza, D.C. Endringer, and R. Scherer, 2017. Seasonal variation affects the composition and antibacterial and antioxidant activities of Thymus vulgaris. Industrial Crops and Products V:95, 543-548. 
Lenka, D., B. Jana, B. Dominika and J. Klaudia, 2015. Effect of drying methods on content of some natural pigments in Utica Dioic L. and Melissa Officinalis L. J Microbiol Biotech Food Sci., 5 (2) : $182-185$.

Meydev, S., I. Sagy, and I.J. Kopelman, 1977. Browning determination in citrus products. J. Agric. Food Chem., 25(3): 502-604.

Mirahmadi, S.F., R. Norouzi and N.M. Ghorbani, 2017. The Influence of Drying Treatments on the Essential Oil Content and Composition of Melissa officinalis L. Compared with the Fresh Sample. J. of Medici. Plants, 16(61): 68-78

Milevskaya, V.V., Z.A. Temerdashev, T.S. Butyl'skaya and N.V. Kiseleva, 2017. Determination of phenolic compounds in medicinal plants from the Lamiaceae family. J. Anal. Chem. 72 (3): 342-348.

Murat, E. and T. Sefa, 2019. The Change of Drying Time and Quality Parameters of Lemon Balm (Melissa officinalis L.) with Different Temperature Profiles of Drying Air. Journal of New Results in Engineering and Natural Science, No. 9: 1-10.

Patora, J., T. Majda, J. Gora, and B. Klimek, 2003. Variability in the content and composition of essential oil from lemon balm (Melissa officinalis L.) cultivated in Poland. J. Endocrinol. Invest. 26: 950- 955 .

Pirbalouti, A.G., S. Salehi and L. Craker, 2017. Effect of drying methods on qualitative and quantitavi properties of essential oil from the aerial parts of coriander. Journal of Applied Research on Medicinal and Aromatic Plants, 4:35-40.

Prawal, P.S.V., R. Laiqur and J.R. Bahl, 2015. Lemon Balm (Melissa officinalis L.) An Herbal Medicinal with Broad Therapeutic Uses and Cultivation Practices: A Review. International Journal of Recent Advances in Multidisciplinary Research, 2: 928-933.

Singleton, V.L., R. Orthofer, and R.M. Lamuela-Raventós, 1999. Analysis of Total Phenols and other Oxidation Substrates and Antioxidants by Means of Folin-Ciocalteu Reagent. Methods in Enzymology, 299:152-178.

Sellami, I.H., W.A. Wannes, I. Bettaieb, S. Berrima, T. Chahed, B. Marzouk and F. Limam, 2011. Qualitative and quantitative changes in the essential oil of Laurus nobilis L. leaves as affected by different drying methods. Food Chem., 126: 691-697.

Sellami, I.H., I.B. Rebey, J. Sriti, F.Z. Rahali, F. Limam and B. Marzouk, 2011. Drying sage (Salvia officinalis L.) plants and its effects on content, chemical composition, and radical scavenging activity of the essential oil. Food and Bioprocess Technol., 5: 2978-2989.

Shakeel, R., L. Romaisa, A. Khursheed, A. Mohammed, S. Abdul, and C. Suresh, 2017. Comparative analysis of the aroma chemicals of Melissa officinalis using hydrodistillation and HS-SPME techniques. Arabian Journal of Chemistry, 10: s2485-s2490.

Skrovankova, S., L. Misurcova, and L. Machu, 2012. Antioxidant Activity and Protecting Health Effects of Common medicinal Plants. Elsevier Inc.: Amsterdam, The Netherlands, 75-139.

Somers, T.C., 1971. The polymeric nature of wine pigments. Phytochemistry, 10: 2175.

Somers, T.C., 1972. The nature of color in red wines. Food Technol. Aust. 24:10.

Yang, C.M., K.W. Change, M.H. Yin, and H.M. Hang, 1998. Methods for the determination of the chlorophylls and their derivatives. Taiwania, 43(2).

Zhisen, J., 1999. The determination of Flavonoids content in mulberry and their scaveing effect on superoxide radicals. Food Chem. 64: 555-559. 